\title{
A CAUSALIDADE EM DELEUZE: DIFERENÇA INTERNA E PRODUÇÃO DE SI
}

\author{
Alessandro Carvalho Sales ${ }^{* *}$ \\ alessandro_sales@uol.com.br
}

RESUMO O artigo procura acompanhar as linhas de força envolvidas na concepção deleuzeana de causalidade, particularmente em suas distâncias para com as noções equivalentes no mecanicismo, no platonismo e no hegelianismo. O interesse é ressaltar como tal noção, desde que sublinhada como causalidade interna ou causa sui, favorece o estabelecimento da diferença como origem do ser, requisito ontológico fundamental no pensamento de Deleuze. Para tanto, mostraremos, argumentando em favor da pertinência do comentário de Michael Hardt, o contexto que, atravessando especialmente as relações de Deleuze com a produção de Bergson, situa a causalidade na imanência, na mesma medida em que a afasta do território da negação. Nessa direção, vamos nos valer ainda de aspectos vinculados a uma interessante controvérsia de tradução.

Palavras-chave Causalidade; Diferença; Deleuze; Bérgson; Hardt.

ABSTRACT The paper aims to follow the central aspects of Deleuze's conception of causality, especially in its contrast to equivalent notions of Mecanicism, Platonism and Hegelianism. The point is to highlight how this notion, once emphasized as internal causality or causa sui, favors the establishment of difference as the origin of being, basic ontological requirement

* Este trabalho é parte da tese de doutorado intitulada Deleuze, o signo e o problema da comunicação: pensamento e acordo discordante, financiada pela FAPESP e defendida em março de 2008 no Departamento de Filosofia da Universidade Federal de São Carlos. Artigo recebido em jul. 2008 e aprovado em 30 maio 2009.

** Doutor em Filosofia pela UFSCar.

KRITERION, Belo Horizonte, no 119, Jun./2009, p. 215-231. 
in Deleuzes 's thought. Therefore, we will show the relevancy of Michael Hardt's comments in order to show the context that, crossing particularly Deleuze's dialogue with Bergson, places causality in immanence, and, at the same time, moves it away from negation's domain. This way, we will pay attention to some aspects related to an interesting translation controversy.

Keywords Causality; Difference; Deleuze; Bergson; Hardt.

Um dos pontos mais fortes da leitura de Michael Hardt em Gilles Deleuze: um aprendizado em filosofia, diz respeito ao problema da causalidade. De acordo com ele, o pensador francês não valoriza outro tipo de causalidade que não aquela interna, eficiente. Determina esta posição de Deleuze já em suas primeiras interpretações sobre Bergson, nos textos de $1956,{ }^{1}$ e diz que ela o acompanhará até o final de suas produções. Afirma o autor: "Eu argumentei que a causalidade eficiente oferece, de fato, uma chave para uma abordagem coerente de todo o discurso de Deleuze sobre a diferença." 2 Em que consiste esta chave? Ela é mesmo iluminadora quanto à compreensão do conjunto de escritos de nosso autor?

Antes de mais nada, deixemos patente o fito maior de Deleuze, já àquela época cristalinamente enunciado:

Para julgar acerca do mais importante, é preciso que se interrogue a respeito do alvo da filosofia. Se a filosofia tem uma relação positiva e direta com as coisas, isso somente ocorre na medida em que ela pretende apreender a coisa mesma a partir daquilo que tal coisa é, em sua diferença a respeito de tudo aquilo que não é ela, ou seja, em sua diferença interna. ${ }^{3}$

Como pensar a pura diferença das coisas? Para Hardt, um dos cernes da interpretação de Deleuze em $A$ concepção da diferença em Bergson expõe as

1 Estes trabalhos são A concepção da diferença em Bergson e Bergson, ambos publicados no Brasil como apêndices ao Bergsonismo (1966a/1999), traduzidos por Lia Guarino e Fernando Fagundes Ribeiro (o primeiro) e Lia Guarino (o segundo). Mais recentemente, essas mesmas traduções foram republicadas no volume $A$ ilha deserta e outros textos (2002/2006), coletânea de escritos deleuzeanos preparada por David Lapoujade, cuja coordenação-geral de tradução, assim como o Bergsonismo, ficou a cargo de Luiz Orlandi. Quando necessário, faremos a referência a partir de A ilha deserta e outros textos. Hardt vai se basear especialmente em A concepção da diferença em Bergson, propondo que o segundo artigo não irá, essencialmente, modificá-lo. Em 1957, Deleuze publica ainda uma seleção de textos de Bergson, Mémoire et vie. Cf. HARDT, 1993/1996, p. 28.

2 HARDT, 1993/1996, p. 17.

3 DELEUZE, 1956a/2006, p. 47-48. 
críticas que este dirige ao mecanicismo, ao platonismo e ao hegelianismo, e precisamente na medida em que estas três correntes teóricas apresentariam uma noção falsa, ilusória da diferença.

Não há dúvidas de que o lance mais delicado de uma tal empreitada fará referência a Hegel. Como atuará Deleuze para não se deixar colher pela malha arguta e envolvente cerzida pelo trabalho do negativo? Como criticar Hegel e escapar da negação sem que este movimento seja apenas mais um passo da própria dialética, dando lugar à recuperação de uma oposição suposta? "Pode parecer, portanto, que, desse ponto de vista, ser anti-hegeliano, mediante uma guinada dialética, vem a ser, mais que nunca, uma postura dialética; com efeito, pode-se argumentar que o esforço para ser um 'outro' para Hegel pode redundar em ser um 'outro' em Hegel."

Hardt indica uma das estratégias de Deleuze, qual seja, a princípio buscar não investir diretamente contra a dialética. Isto seria outorgar imediata vantagem ao rival: cedendo o "mando de campo", Deleuze estaria combatendo em solo adversário. Introduzindo em cena alguns mediadores, será contra eles que as primeiras pelejas serão travadas: no caso da leitura de Bergson, mecanicismo e platonismo são os intercessores do negativo; no livro sobre Nietzsche, tal papel caberá a Kant. ${ }^{5}$ De todo modo, em ambos os casos, pressentimos o inimigo mais forte na subjacência: Hegel.

A vantagem que há em dirigir-se primeiro a esses inimigos próximos é a de que eles fornecem uma base comum sobre a qual elabora o ataque que pode ser subseqüentemente estendido à dialética (...) Mais importante, ainda, esse método de triangulação nos mostra que mesmo nessa obra inicial Deleuze tem uma relação problemática com a oposição. É claro que Deleuze está atacando a dialética como o inimigo fundamental, mas esse método lhe permite adotar uma postura oblíqua com relação a Hegel, de tal forma que ele não tem que se colocar em oposição direta. ${ }^{6}$

Tudo se passa como se Hegel elevasse ao máximo limite, potencializasse ao extremo, o possível descaminho das demais linhas teóricas mencionadas: tanto mais por isto, ei-lo como o mais perigoso e ardiloso dos adversários. Para chegar a ele, Deleuze passa antes pelos seus "partidários" — mas, já ao criticá-los, é Hegel quem está na mira fina. Segundo Hardt, é apenas neste artigo inicial que ele chega a uma crítica algo direta, em termos hegelianos até,

4 HARDT, 1993/1996, p. 11-12. Cf. a introdução do livro de HARDT (1993/1996), intitulada Hegel e as fundações do pós-estruturalismo, p. 9-17. Cf. também, na mesma obra, a nota O fim do anti-hegelianismo de Deleuze, à p. 95.

5 Cf. HARDT, 1993/1996, p. 30-31.

6 HARDT, 1993/1996, p. 31. 
à dialética. A partir de então, ele sempre vai mexer com "uma extrapolação ou derivação da dialética". ${ }^{7}$ Que crítica é esta?

Trata-se de uma crítica ao processo negativo de determinação. O comentador apresenta esta questão, lembrando que está aí em jogo a interpretação que Hegel dá de uma frase de Espinosa, "Omnis determinatio est negatio", situando-a como ponto de convergência de sua Ciência da Lógica e como espécie de definição do mecanismo dialético: que toda determinação seja, de modo imediato, uma forma de negação, processo conduzido ao cerne do ser e, portanto, implicado na fundamentação de um estatuto ontológico para o negativismo.

Como começar o pensamento? A visada da Fenomenologia do Espírito — diante da recomendação de eliminar qualquer pretensão incluída na ideia da aplicação de um método, como tal, de saída exterior ao conhecimento e irrevogavelmente alheio ao mesmo - conduzia a consciência à atitude de contemplação do imediato da certeza sensível para que aí encontrasse a forma de seu próprio desenvolvimento autônomo. Na Lógica, tratar-se-ia de assumir postura semelhante - encontrar um começo idealmente livre de pressupostos - agora não mais diante da experiência necessária da consciência, mas da forma conceitual necessária do ser. Para isso, vai buscar o imediato no ser puro, o qual, por simples, encontra-se livre de toda determinação — qualidades, categorizações, limites —, tratando-se, enfim, do próprio indeterminado sob cuja figura o ser revela ser o nada. Esse ser vazio de modo algum é resultado de uma determinação, uma vez que esta pressupõe justamente a série das diferenças descartada pelo desejo de se conferir um caráter puro ao início do processo. Ele é o não determinado, condição da determinação: se ele é sem limites, ainda que vazio, deve conter em si toda a série dos possíveis.

$\mathrm{O}$ advento de uma diferença, porém, exige que o ser negue o nada que lhe constitui, e a determinação então gerada não pode deixar de reeditar a contraposição essencial entre ambos: "O ser determinado subsume essa oposição, e essa diferença entre o ser e o nada em seu próprio núcleo define a fundação das reais diferenças e qualidades que constituem a sua realidade." $\mathrm{Na}$ verdade, não se trata exatamente de oposição porque o nada é componente do ser, forma com ele uma unidade que se manifesta como existência em qualquer determinidade. Hardt explica que essa condição da determinação define-se pela negação tanto na direção do contraste - o conjunto finito das qualidades que se opõem reciprocamente de modo automático e passivo (uma 
determinação difere de todas as outras determinações) — quanto na direção do conflito - do combate dinâmico praticado pelas diferenças entre si e que envolve a perspectiva de um exercício de engajamento numa posição de atividade devido às relações causais existentes entre os elementos constituintes da determinidade: neste nível, "a existência de algo é a negação ativa de algo mais". ${ }^{9}$ A importância de sublinhar esse segundo sentido da presença da negação na determinação reside no fato de que ele torna explícito o movimento negativo que define o ser determinado, inclusive quando considerado de modo estático: o estado "determinado" já é em si dinâmica da negação. O processo de determinação nega o nada do ser, mas o faz considerando-o, pois, para Hegel, sem ele, teríamos a plena unidade da substância (Espinosa) e nenhuma diferenciação: “(...) o ser não determinado pela negação permanecerá indiferente e abstrato e, finalmente, uma vez que não é posto como diferente de seu oposto, desaparecerá no nada."10 Noutras palavras, só seria possível pensar o processo lógico de produção da determinidade mediante a negação da negação.

Entrevemos como a questão acabará por se apresentar a Deleuze: se Hegel, para resguardar o papel da negação, precisava considerar impossível desenvolver a presença da determinidade diante de um ser puro, pleno e totalmente positivo, tratar-se-á para ele de, ao contrário, buscar engendrar uma forma de pensar o processo gerativo da diferença como ser positivo - o que certamente significará afirmar Espinosa e desvalorizar o papel da negação, eliminando a passagem por Hegel. Mas atentemos para o encaminhamento sugerido por Hardt. Depois da apresentação da determinação hegeliana, ele segue a sua perspectiva dizendo:

(...) Deleuze assevera que o próprio processo de determinação ontológica solapa a fundamentação real do ser; ele afirma que a diferença constituída pelo movimento negativo da determinação é uma noção falsa da diferença. Por isso, o processo de determinação tanto destrói a natureza substancial do ser quanto fracassa na apreensão da concretude e especificidade do ser real. ${ }^{11}$

Veremos que este duplo fato - a demolição da natureza do ser e o consequente fracasso quanto à sua apreensão — será atribuído precisamente ao tipo de causalidade posta em jogo pela dialética. Hardt passa a seguir a crítica bergsoniana de Deleuze aos mecanicistas, a Platão, para depois retornar 
a Hegel. Observemos o que é dito quanto ao mecanicismo e, logo a seguir, a hipótese que Hardt vai buscar sustentar. Para mostrar que o mecanicismo também aniquila o ser em sua necessidade, ele se vale do seguinte fragmento do texto A concepção da diferença em Bergson:

Contra um certo mecanicismo, Bergson mostra que a diferença vital é uma diferença interna. Mas ele também mostra que a diferença interna não pode ser concebida como uma simples determinação: uma determinação pode ser acidental, ao menos ela só pode dever o seu ser a uma causa, a um fim ou a um acaso, implicando, portanto, uma exterioridade subsistente (...). A diferença vital não só deixa de ser uma determinação, como é ela o contrário disso; é, se quiser, a própria indeterminação. Bergson insiste sempre no caráter imprevisível das formas vivas: "indeterminadas, quero dizer, imprevisíveis"; e, para ele, o imprevisível, o indeterminado não é o acidental, mas, ao contrário, o essencial, a negação do acidente. ${ }^{12}$

Hardt acentua que, no bergsonismo de Deleuze, a determinação mecanicista é acidental, na medida em que ela estabelece o ser de uma diferença em função de um "outro", seja ele uma causa, uma finalidade, um acaso. O ser não se coloca por si, em si, essencialmente, mas depende sempre de uma exterioridade que o provoque e disponha, e é nesta relação que ele ganha a sua determinação, a sua previsibilidade, a sua possibilidade de cálculo. Vemos que, para Bergson e para Deleuze, não é o imprevisível que é acidental; ao contrário, é no reino do imprevisível que se situa a essencialidade do ser: prevê-lo, determiná-lo, é que será um acidente. A determinação não implica uma essência, mas um acidente provocado por uma exterioridade subsistente, não necessária, e eis que Deleuze, com Bergson, pode falar de uma certa indeterminação. ${ }^{13}$

Hardt considera muito singular a postura deleuzeana, justamente porque ela consiste numa espécie de inversão ontológica (como de outro modo vimos acima), ponderando que o que está em pauta não é verificar como o ser pode ganhar algum tipo de determinabilidade, mas como a diferença pode sustentar, prover o seu ser. ${ }^{14}$

Observemos que há aí uma questão concernente à tradução da sentença elle ne peut tenir son être que d'une cause, d'une fin ou d'un hasard. ${ }^{15} \mathrm{~A}$

12 DELEUZE, 1956a/2006, p. 56-57. Há um interessante detalhe de tradução sobre o qual breve discorreremos. Citado parcialmente por HARDT, 1993/1996, p. 31.

13 Cf. HARDT, 1993/1996, p. 31.

14 Cf. HARDT, 1993/1996, p. 32. No texto original, o acesso mais simples ao texto La conception de la différence chez Bergson é, como já comentamos, na seleção L'lle déserte et autres textes, levada a termo por David Lapoujade, p. 43-72. Eis o contexto um pouco mais amplo: "une détermination peut être accidentelle, du moins elle ne peut tenir son être que $d$ 'une cause, $d$ 'une fin ou d'un hasard, elle implique donc une extériorité subsistante" (DELEUZE, 1956b/2002, p. 55).

$15 \mathrm{O}$ trecho em francês chega a ser citado, na obra de Hardt, em três momentos: duas vezes como "elle ne peut tenir son être que d'une cause, d'une fin ou d'un hasard" e uma vez como "peut tenir son 
edição brasileira do texto de Deleuze optou — corretamente — por "ela só pode dever o seu ser a uma causa, a um fim ou a um acaso", enquanto a interpretação de Hardt quer fazer valer um outro sentido: no inglês, ele verte tenir em support, ${ }^{16}$ de modo que ao invés do caminho mais literal tomar de, dever seu ser a, ficamos mais perto daquele por ele empregado com sustentar seu ser através de.

Atendo-se tão somente ao fragmento peut tenir son être, ${ }^{17}$ isolando-o e traduzindo tenir por to support, o comentador enfatiza aí o investimento do filósofo francês: como sustentar o ser? O que pode sustentar o ser? Mas não há um largo espaço entre dever seu ser a e sustentar seu ser? Pois bem, é neste espaço mesmo que podemos cavar todo o caminho do pensamento de Deleuze.

Enquanto a primeira expressão apresenta uma ideia clara e direta de subordinação externa (e certamente assim ponderou Deleuze quanto ao trecho em questão: no mecanicismo criticado por Bergson, a determinação realmente deve seu ser a uma exterioridade - a transitividade do verbo, aliás, é incontornável), a segunda nos joga em um contexto de mais independência: sustentar o ser pode muito bem ser fornecê-lo por si, provêlo independentemente de um outro, o que imprime um sentido praticamente oposto ao primeiro.

Ocorre porém que Deleuze não usa soutenir - palavra francesa que sem dúvida "colaria" melhor no sentido proposto por Hardt -, mas tenir. De todo modo, como dissemos, Hardt descontextualiza o fragmento - ao omitir a preposição e, por conseguinte, esvaziando a transitividade do verbo instaurando a sua versão, na qual to support, veremos, será conveniente e didático. A partir daí, não à toa, inúmeras vezes, ao longo de seu escrito, ele utiliza o verbo (to support) ou o substantivo (support). ${ }^{18}$

Até onde pudemos perceber, na leitura atenta que buscamos executar de $L a$ conception de la différence chez Bergson, Deleuze não se vale em nenhum outro instante de tenir nem de soutenir. Enfim, Hardt - tendo ou não consciência, pouco importa — parece realizar uma pequena torção no texto de Deleuze,

être". Cf. o texto inglês, acessível na internet, no endereço <http://www.duke.edu/ hardt/>, link The Art of organisation. Na tradução brasileira, a menção ao francês não deixou de ser feita em duas ocasiões (cf. HARDT, 1993/1996, p. 31 e 32). Na terceira, a tradutora verteu diretamente a frase - que no texto original estava em francês - para o português, empregando "pode apenas sustentar o seu ser através de uma causa, uma finalidade, ou um acaso", obviamente endossando a postura de Hardt. Neste terceiro caso, cf. HARDT, 1993/1996, p. 33.

16 Cf. o texto inglês de Hardt, <http://www.duke.edu/ hardt/>, link The Art of organisation.

17 Como faz Hardt: cf. 1993/1996, p. 32.

18 Remetemos novamente ao texto original de Hardt, no endereço eletrônico outrora indicado. 
perspectivando-o com base na partícula exibida. ${ }^{19}$ Fazendo-o, irá angariar melhor apoio à sua própria ideia. Mas o que, então, nos interessa nisto tudo?

Mesmo que a tradução de Hardt esteja equivocada, a hipótese a ser realçada é que ela talvez não deixe de ser esclarecedora, iluminadora, embasando a ideia que virá a seguir. Ainda que possivelmente ele tenha forçado um pouco a mão na tradução do fragmento, uma das questões que parecem emanar o tempo todo do texto $A$ concepção da diferença em Bergson é mesmo aquela relativa a uma espécie de sustentabilidade insubordinada do ser, isto é: como o ser pode se sustentar por si, em si, sem a dependência de causas externas? Errando a tradução, Hardt conseguirá ainda acertar seu alvo? Façamos esta concessão e sigamos em sua leitura. Adiante, teremos condição de realizar uma avaliação mais segura. Embora já a tenhamos pressentido, qual é então a proposta?

Não se trata de tentar — de fora - capturar o ser das coisas, determinálo, com a ajuda e a aplicação de esquemas conceituais variados, sempre prontos, preconcebidos (de antemão, isto implicaria perdê-lo, encaixando-o nas paredes da representação), mas sim buscá-lo, por si, lá onde ele se produz, na sua origem, em suas mínimas e derrisórias colunas de apoio (para fazer valer a fraseologia de nosso intérprete), ou seja, onde ele é em sua mais fina e imprevisível diferença, necessariamente interna. A diferença interna, nesta visão, é produtora do ser:

Deleuze atribui à diferença um papel radicalmente novo. A diferença funda o ser; proporciona ao ser a sua necessidade, a sua substancialidade. Não podemos compreender esse argumento da supremacia da diferença interna sobre a diferença externa a menos que reconheçamos o papel ontológico fundamental que a diferença é chamada a representar. ${ }^{20}$

Hardt dá a entender que a melhor forma de compreender o estatuto ontológico da diferença tal como rigorosamente a propõe Deleuze é através da remissão à escolástica, quanto aos temas ontológicos da causalidade e da produtibilidade do ser, e já a partir de sua primeira leitura de Bergson. ${ }^{21}$ Neste caso, ele sugere dois detalhes que poderiam de antemão contribuir para um eco escolástico: o próprio interesse de Deleuze pelo assunto (por Duns Scott em particular) e o conhecimento que Bergson tinha de Aristóteles. ${ }^{22}$ Mas, de

19 Talvez possamos inquerir: mas não é assim também que o próprio Deleuze procede em muitas de suas interpretações? Cf., por exemplo, a famosa Carta a um crítico severo, em DELEUZE, 1990/1992, p. 11-22.

20 HARDT, 1993/1996, p. 32.

21 Cf. HARDT, 1993/1996, p. 32.

22 Cf. HARDT, 1993/1996, p. 32. 
uma maneira geral, ele acentua: "O que considero mais importante em relação à obra de Deleuze é o modo escolástico de reflexão ontológica e os critérios que estabelece para o ser." ${ }^{\prime 23}$ Isto nos pareceria uma contribuição fecunda para a interpretação de Deleuze. Resta saber de seu funcionamento e de sua possível eficácia.

O pensador americano utiliza Etienne Gilson, num comentário a Duns Scot, para afirmar que a base da ontologia escolástica é firmada sobre a causalidade e a produtibilidade, aptidões reversíveis, propriedades complementares do ser: produzir e ser produzido. ${ }^{24}$ Ele aponta que, no debate escolástico sobre a ontologia, é notável a atenção minuciosa que os pensadores depositam no trato dos problemas que envolvem a causalidade. ${ }^{25}$ Aí, a relevância de dois princípios é salientada: “(1) um efeito não pode ter mais perfeição ou realidade que a sua causa; (2) uma coisa não pode ser a causa necessária de algo fora de si mesma." ${ }^{26}$

Finalmente, outro movimento importante no raciocínio de Hardt é apontar um certo deslocamento da relação ser-causalidade entre o escolasticismo e Espinosa. No escolasticismo: (1) a essência divina é produtiva, atuando como causa primeira, a causa eficiente de tudo; (2) embora a causa eficiente seja a mais importante no que se refere às provas da existência de Deus, os escolásticos preservam os 4 tipos de causa propostos por Aristóteles como causas reais, ainda que lhes alterem a interpretação. ${ }^{27}$ Em Espinosa: (1) Deus não é uma causa primeira sem causa, mas causa de si mesmo, isto é, causa sui; (2) repelindo, especialmente contra Descartes, as causas formal e final, as únicas causas concebidas como reais são as causas eficientes. ${ }^{28}$ Eis que chegamos ao Deleuze de Hardt, para quem só vai interessar a causa eficiente, interna, a única capaz de sustentar o ser em sua mínima corporeidade, em sua mais distante e modesta materialidade.

Não temos que nos afastar muito do texto para ler a afirmação de que a determinação "pode apenas sustentar o seu ser através de uma causa, uma finalidade, ou um acaso" como um ataque às três concepções da causalidade que são inadequadas à fundação do ser: (1) material - uma causa puramente física que ocasiona um efeito externo; (2) final - uma causa que se refere a uma finalidade ou meta na produção de seu efeito; (3) acidental - uma causa que tem uma relação completamente contingente com o seu efeito. O que é central em cada caso é que a causa permanece externa a seu efeito

23 HARDT, 1993/1996, p. 32.

24 Cf. HARDT, 1993/1996, p. 32; e GILSON, 1962/2001, p. 740-741.

25 Cf. HARDT, 1993/1996, p. 32.

26 HARDT, 1993/1996, p. 32.

27 Cf. HARDT, 1993/1996, p. 32.

28 Cf. HARDT, 1993/1996, p. 33. 
e assim pode apenas sustentar a possibilidade do ser. Para que o ser seja necessário, a causa ontológica fundamental deve ser interna ao seu efeito. Essa causa interna é a causa eficiente que desempenha o papel central nas fundações ontológicas da Escolástica. Além disso, somente a causa eficiente, em razão de sua natureza interna, é que pode sustentar o ser como substância, como causa sui. ${ }^{29}$

Tentando pensar a diferença ainda distante de sua relação com qualquer outro, Hardt ratifica a necessidade bergsoniana de Deleuze de chegar às diferenças em si, em sua gênese, envolvidas em seus estados dinâmicos produtivos nascentes. De acordo com ele, "por meio dessa dinâmica produtiva interna, o ser da diferença eficiente é causa sui." ${ }^{30}$ A estes dinamismos produtivos, Bergson chamará diferenciação, dando a ver, segundo a expressão de Deleuze, a "força explosiva interna que a vida traz em si." 31 Talvez possamos, neste momento, tecer algumas poucas considerações e ilações a respeito do que até aqui foi visto, antes de prosseguirmos com o desfecho das proposições de Hardt.

Tudo se passa como se, montando o debate em torno do problema da causalidade, Hardt, por uma outra via, nos levasse às distâncias entre a imanência e a transcendência. Sabemos da luta de Deleuze em fazer valer uma perspectiva imanentista quanto à decifração do real, em contraponto a todo tipo de transcendência. Diz ele ao final do seu primeiro texto bergsoniano: "A diferença é que é explicativa da própria coisa, e não suas causas." $32 \mathrm{Com}$ Hardt, vimos justamente que Deleuze descarta todo tipo de causalidade que não seja interna. Pois bem, estas causas que foram rejeitadas, elas o foram porque, de uma maneira ou de outra, permanecem exteriores, ou melhor, transcendentes, quanto à diferença que se procura apreender, quanto ao objeto que se tenciona pensar.

Neste caso, em vez de tentar perseguir um objeto qualquer em suas linhas complexas e próprias de desenvolvimento imanente, recorre-se a um mediador, a uma alteridade externa e já modelada, habilitada para lhe aparar as verdades acabadas, desde que elas possam ser conformadas, assimiladas, ao espelho que lhes é anteposto: ideias prontas, prévias, justas. Vemos então no objeto exatamente o que já estava previsto, vemo-lo conforme o combinado, segundo o espelho, o plano, em que sua imagem é refletida. Deforma-se assim o objeto em sua diferença mais preeminente, e o que se obtém é uma imagem

29 HARDT, 1993/1996, p. 33.

30 HARDT, 1993/1996, p. 33.

31 DELEUZE, 1956a/2006, p. 57. Expressão citada por HARDT, 1993/1996, pelo menos em três pontos: p. 44, 47 e 54.

32 1956a/2006, p. 71. 
degradada, ilusória, categorizada, representada, do que realmente está em jogo.

A causa valorizada por Deleuze é eficiente e interna, aliás, imanente: causa sui. Refratário às exterioridades transcendentes que tencionariam colhê-lo em esquemas prévios, encontrar um objeto em termos de causa sui, sua essência imanente, não poderá ser representá-lo. De outro modo, como então apreendê-lo? Gerando-o, produzindo-o. Atingimos um ponto crucial do pensamento de nosso autor, que o seguirá sempre, e que lhe foi amplamente confirmado por Bergson: diferenciar é criar, diferença é criação, algo que se dá, em princípio, longe de modelos exteriores e transcendências variadas. Avistamos toda uma inversão: não se tratará aí de simples mimetismo do real, mera reprodução do mundo segundo suas figuras sempre previdentes e cada vez mais disseminadas, mas sim de criar o real e o mundo, de produzi-los na contenda da imanência, sem a plena e característica subordinação a pontos de vista externos. Tudo isto, por sinal, será ainda indissociável das relações com as subjetividades: na invenção do mundo, o si também é o que se reinventa. Obviamente, estamos diante de toda uma outra paisagem para a filosofia, com inumeráveis consequências. Esperamos desenvolver e constatar algumas ao longo das páginas deste trabalho.

Retornemos a Hardt. Trata-se agora de acompanharmos a crítica que Bergson, lido por Deleuze, dirige a Platão, procurando valorizar as recentes proposições de nosso comentador. Em Platão, a diferença da coisa está associada, mais uma vez, a uma exterioridade. Ora, o apoio externo, aqui, é evidente, e diz respeito às essências transcendentes que permanecem acima de tudo, no suprassensível, modelos metafísicos que deverão ser suficientemente introjetados, assimilados pelas cópias sensíveis. Este mundo inteligível é causal relativamente ao sensível. Um desses modelos é superior e reúne os demais: a Ideia de Bem funciona como um guia maior, a plena inspiração que paira sobre o mundo sensível. Há um finalismo em Platão: "a diferença da coisa pode apenas ser explicada por sua destinação, o Bem. Se traduzirmos essa afirmação em um discurso causal, podemos dizer que Platão tenta fundar o ser na causa final" ${ }^{33}$ Em função do estabelecimento destas idealidades pertencentes a um outro mundo, idealidades que deveriam ser tão perfeitamente copiadas quanto possível pelos seres terrenos, o platonismo é um dos exemplos mais bem acabados de causalidade exterior e transcendente, na ótica deleuzeana. 
Podemos aqui verificar um pouco mais de perto algumas das consequências de se tentar pensar uma causalidade imanente, interna. No platonismo, o inteligível é normativo, regulador, do sensível. Um dos resultados mais evidentes é a desqualificação do mundo sensível: o inteligível — com suas essências perfeitas, eternas e imutáveis - é primeiro, de modo que mesmo a mais bem acabada realidade do sensível virá em segundo lugar. ${ }^{34} \mathrm{Na}$ esteira nietzscheana, eis aí tudo aquilo de que Deleuze quer se evadir: o mundo como um mundo moral. ${ }^{35}$

Escapar do mundo moral, para Deleuze, será valorizar ao extremo o sensível. Obviamente, as idealidades filosóficas não poderão deixar de ter relação com o sensível, mas esta é considerada apenas em termos de sua condição imanente. Seguramente, os referenciais exteriores, transcendentes, não serão apreciados. Perpétua deriva? De modo algum. Não se trata de dispensar as referências: delas sempre necessitaremos, não há como não estarem presentes. Porém, elas não serão absolutizadas. As referências são geradas, utilizadas e também descartadas no vínculo imediato com os contextos em pauta, o complexo de forças em questão: propensão à imanência.

$\mathrm{O}$ contraponto entre a causalidade transcendente platônica e uma causalidade imanente, interna, é apontado por Émile Bréhier, no livro $L a$ théorie des incorporels dans l'ancien stoücisme, obra muito estimada por Deleuze em sua Lógica do sentido. Diz Bréhier, relativamente ao pensamento estoico que "la cause est (...) véritablement l'essence de l'être, non pas un modèle idéal que l'être s'efforce d'imiter, mais la cause productrice qui agi en lui, vit en lui et le fait vivre." ${ }^{36}$ Eis aí, mais uma vez, a força explosiva interna que a vida traz em si: causa produtora, causa de si, pauta que Deleuze apreende mais efetivamente já em seu primeiro Bergson e que vai levar até o fim de sua produção.

Hardt aproveita o ensejo da crítica bergsoniana de Deleuze a Platão para ratificar uma das características da causalidade ora apreciada, enunciando que aí "(...) não há separação entre a diferença e a coisa, entre a causa e o efeito". ${ }^{37}$ Quanto a isto, prezando a imanência em filosofia e sempre tentando desviarse das regras da representação, das ideias gerais, recorramos diretamente ao texto de Deleuze, no qual o veremos citando Bergson, ao marcar que o jogo é cinzelar "pour l'objet un concept approprié à l'objet seul, concept dont on

34 Cf. DELEUZE, 1966b/1998, p. 259-271.

35 Este ponto de vista é capaz de condensar, muito provavelmente, grande parte do desenvolvimento da obra de Deleuze.

36 BRÉHIER, 1928/1980, p. 5.

37 HARDT, 1993/1996, p. 34. 
peut à peine dire que ce soit encore un concept, puisqu'il ne s'applique qu'à cette seule chose". ${ }^{38}$ De algum modo, vemos a travessia de Deleuze entre sua primeira e sua última filosofia: a unidade da coisa e do conceito ${ }^{39}$ é algo que se trama com diferenças imanentes - especialmente quando a coisa é também um conceito e o que assim se tece é o conceito de conceito. ${ }^{40}$ Dar conta cada vez mais e melhor destas diferenças, destas singularidades, aliás, pensá-las: esta a tarefa a que as pesquisas do autor estarão permanentemente dedicadas.

Na sequência, Hardt busca se valer, mais uma vez, da tradição escolástica para, numa linha muito próxima da questão causal, estabelecer as distâncias entre diferenças de natureza e diferenças de grau, terminologias bergsonianas que são caras a Deleuze, na medida em que são definidoras da distinção entre o campo do necessário e o campo do casual: "As diferenças de natureza' aparecem como aquelas diferenças que implicam necessidades e substância, correspondendo à causae per se escolástica; assim, 'diferenças de grau' são aquelas que implicam acidentes, causae per accidens". ${ }^{41}$ Adicionando novas nomenclaturas, vemos na realidade que a relação básica inicial permanece: a causae per se diz respeito à causalidade interna, imanente, enquanto a causae per accidens refere a externa, transcendente. Assim, mecanicismo e platonismo atingem apenas diferenças contingentes (per accidens), ao passo que o ponto de vista bergsoniano nos conduz às diferenças essenciais (per se) ${ }^{42}$

Chegamos mais fortemente à crítica que Deleuze dirige a Hegel, a partir de sua leitura de Bergson, ápice de todo o processo, uma vez que o hegelianismo é o alvo maior que há nas demais críticas: Hegel firma a diferença numa relação com uma exterioridade absoluta. ${ }^{43}$ Eis o fragmento, aqui mais completo, que é citado por Hardt:

(...) a partir de alguns textos de Bergson, pode-se prever as objeções que ele faria a uma dialética de tipo hegeliano, da qual, aliás, ele está muito mais longe do que daquela de Platão. Em Bergson (...) a coisa, inicialmente, difere imediatamente de si mesma. Segundo Hegel, a coisa difere de si mesma porque ela, primeiramente, difere de tudo o que ela não é, de tal maneira que a diferença vai até à contradição. ${ }^{44}$

38 BERGSON, 1903-1923/1969, p. 125. Observemos o quanto, já neste texto sobre Bergson, Deleuze insiste num outro estatuto para o conceito, não representativo nem categorizante, mas imanente ao objeto. Cf. também 1956a/2006, p. 52 e p. 61-62.

39 Expressão usada em DELEUZE, 1956a/2006, p. 48.

40 O "objeto" de O que é a filosofia? (DELEUZE; GUATTARI, 1991/1992) é o conceito.

41 HARDT, 1993/1996, p. 35.

42 Cf. HARDT, 1993/1996, p. 35.

43 Cf. HARDT, 1993/1996, p. 35.

44 DELEUZE, 1956a/2006, p. 59-60. Citado parcialmente por HARDT, 1993/1996, p. 35. 
Ou seja, Deleuze retoma o problema da determinação e o movimento negativo da dialética. A interpretação de Hardt alinhava este diferir imediatamente de si à diferença da coisa em sua condição de produção imanente, interna, enquanto mecanicismo e platonismo comprometeriam este pilar eficiente do ser na proporção em que o recolheriam já rebatido em suportes externos - um objeto ou fato empíricos no primeiro, uma finalidade no segundo. ${ }^{45}$ De todo modo, em ambos os casos, a exterioridade da diferença ainda é limitada, o que já não é o caso de Hegel, que a dirigirá ao seu limite radical: "A dialética apresenta a coisa diferindo de uma outra ilimitada, 'com tudo que não é' — isso é exterioridade absoluta." ${ }^{46}$

Podemos aqui, dentro deste tema, apontar também a posição de François Zourabichvili. Este adverte que, em Hegel, a diferença é afirmada a partir de uma identidade pressuposta - a identidade de um Todo é um pressuposto implícito. ${ }^{47}$ Ao levar a diferença até a contradição, Hegel a subordina ao idêntico: quando a determinação, na negação que a constitui, é descrita pela oposição ao conjunto absoluto dos possíveis, a consequência é a colocação da diferença na dependência da identidade deste conjunto. ${ }^{48}$

Hardt passa então a dispor o assunto, em se tratando agora de Hegel, segundo a perspectiva da causalidade. Vai colocar que, na dialética da contradição, a causa é necessariamente externa ao seu efeito: o processo de mediação baseado na oposição é o que se dá tão só e exclusivamente em função de um outro sempre externo, e essa externalidade é, em si, incapaz de dar conta do caráter necessário daquilo que se passa no processo gerativo do ser. Eis, segundo Hardt, tudo aquilo que não pode ser avalizado por Deleuze. Ele sentencia:

uma concepção do ser fundada em uma causa externa não pode sustentar a necessidade ou a substancialidade do ser porque uma causa externa ao seu efeito não pode ser necessária; as sucessivas mediações externas que fundam o ser dialético não podem constituir causae per se, mas devem, ao invés disso, ser reconhecidas como causae per accidens. ${ }^{49}$

Além disto, quando o trabalho do negativo torna o ser um acidente, faz dele aquilo que Hegel mais queria evitar: uma abstração. Se a causa de uma oposição a ela permanece externa, a malha assim operada é demasiado larga, 
folgada: o real é extremamente complexo e nuançado a ponto mesmo de não caber em roupas que não sejam as suas - ele sobra, ele vaza pela indumentária dos opostos. "O que não comporta nem graus nem nuanças é uma abstração", diz Deleuze. ${ }^{50}$ Mesmo a síntese dialética seria uma falsa síntese, pois diria respeito apenas à combinação, à reunião entre dois termos, que, ao fim e ao cabo, continuariam externos entre si, sem portanto apresentarem o matizado necessário concernente às cores múltiplas do real. ${ }^{51}$

Finalmente, o que ganhamos com tudo isto? Terá Hardt nos ajudado a compreender um pouco melhor um sentido mais forte das ideias de Deleuze?

A questão centralizada pelo comentador foi a da natureza da causalidade a partir da crítica bergsoniana de Deleuze ao mecanicismo, ao platonismo e ao hegelianismo. No caso do mecanicismo, dada a sobrevalorização de aspectos factuais, uma determinação é o que surge sempre em função de uma exterioridade empírica e de uma relação acidental, de modo que temos uma perspectiva causal pobre, material, que define o ser apenas como contingente. No platonismo, a diferença não é fundada segundo uma causa material, mas final, na proporção em que ela é produzida segundo um finalismo rigorosamente externo e absoluto. Quanto ao hegelianismo - o jogo da determinação que quer definir o que a diferença é opondo-a a tudo o que ela não é, ou seja, segundo um movimento negativo absoluto e externo - , vimos que a causalidade resta acidental e abstrata. Deleuze, com Bergson, defende tão somente a causa interna, eficiente, na medida em que ela é, efetivamente, capaz de constituir o ser como necessário.

Constituí-lo a partir de onde, do que? Não a partir de alteridades externas, mas a partir de diferenças de si, em si, de um contexto interno e enredado capaz de conduzir, em seus dinamismos primeiros, a diferenciação das diferenças. "O movimento do ser é uma progressão de diferenças internas na medida em que a causa é sempre inerente ao seu efeito." 52

Foi assim que fizemos uma relação entre os tipos de causalidade e o par imanência/transcendência. Se ficam desvalorizadas as instâncias causais exteriores, ou melhor, os transcendentes variados, o que resta é uma produção imanente das coisas. E, aí, trata-se mesmo de produção — não de re-produção —, uma vez que há o convite a um desarmamento ativo: sem ideias prontas ou preconcebidas, os objetos, o mundo, são "desenquadrados" e liberados de suas fixações representativas, de modo talvez a se deixarem perceber sob novos

50 1956a/2006, p. 60.

51 Cf. HARDT, 1993/1996, p. 36-37.

52 HARDT, 1993/1996, p. 174. 
ângulos e perspectivas, podendo assim ser novamente criados, gerados de uma outra maneira.

Essa produção interna, imanente, não espera por nada que venha de fora, é o que se faz por si, a partir de si, o que já está sendo feito, que não há como não fazer, causa sui, segundo os movimentos obscuros desta força interna e explosiva que a vida carrega em si. Eis tudo o que Deleuze quer sublinhar.

Ainda numa tal direção podemos voltar a realçar a controvérsia de tradução que há pouco vislumbrávamos. Com a descontextualização do fragmento peut tenir son être e a procedente opção por to support como tenir, Hardt certamente tencionava acentuar o jogo da causalidade interna, aliás, o jogo da imanência. A contrapelo de uma versão mais literal e correta, sua escolha, ratificada diversas vezes ao longo do texto de sua tese, vai dispor a questão da causalidade interna segundo a sustentabilidade do ser. O que efetivamente pode sustentar o ser? Não há como fazê-lo se aquilo que o ampara são suportes externos: estes são sempre acidentais, limitados. Sustentar o ser será provêlo desde que sem a plena dependência de guias externos: autoprovimento. Assim, a sustentabilidade ontológica solicitada pelos escritos de Deleuze e apontada por Hardt é insubordinada e implicará o ser como autoposição. ${ }^{53}$

De outra maneira, verificamos que as distâncias entre sustentar seu ser e tomar ou dever seu ser a expõem uma fenda na qual podemos, talvez, depositar boa parte do novo das proposições deleuzeanas. É que a segunda expressão requer a transitividade, uma alteridade complementar, já mesmo em termos de linguagem, ao passo que a primeira enfeixa melhor um sentido positivo de suficiência, de autocriação. Conduzindo sua tradução por esta via, é provável que Hardt esteja cometendo uma pequena falta. Entretanto, notavelmente, temos a impressão de que se trata de um equívoco fértil, produtivo: ele dá bem a ver um tecido importante situado no coração do pensamento de Deleuze, clarificando-o.

\section{Referências}

BERGSON, Henri (1934). La pensée et le mouvant: essais et conférences. Paris: Presses Universitaires de France, 1969.

53 Essa condição será trabalhada, e de maneira muito clara, por exemplo, em O que é a filosofia? (1991/1992) onde Deleuze e Guattari, no tocante ao conceito, declaram: "Mas o conceito não é dado, é criado, está por criar; não é formado, ele próprio se põe em si mesmo, autoposição (...) Tanto mais o conceito é criado, tanto mais ele se põe. O que depende de uma atividade criadora livre é também o que se põe em si mesmo, independentemente e necessariamente: o mais subjetivo será o mais objetivo" (p. 20). 
BRÉHIER, Émile (1928). La théorie des incorporels dans l'ancien stoïcisme. Paris: Librairie Philosophique J. Vrin, 1980.

DELEUZE, Gilles (1956a). A concepção da diferença em Bergson. In: DELEUZE, Gilles. A ilha deserta e outros textos: textos e entrevistas (1953-1974). São Paulo: Iluminuras, 2006.

DELEUZE, Gilles (1956b). La conception de la difference chez Bergson. In: DELEUZE, Gilles. L'lle deserte et autres textes: textes et entretiens (1953-1974). Paris: Les Éditions de Minuit, 2002.

DELEUZE, Gilles (1956c). Bergson. In: DELEUZE, Gilles. A ilha deserta e outros textos: textos e entrevistas (1953-1974). São Paulo: Iluminuras, 2006.

DELEUZE, Gilles (1966a). Bergsonismo. São Paulo: Ed. 34, 1999.

DELEUZE, Gilles (1966b). Platão e o simulacro. In: DELEUZE, Gilles. Lógica do sentido. São Paulo: Perspectiva, 1998.

DELEUZE, Gilles (1990). Conversações. Rio de Janeiro: Ed. 34, 1992.

DELEUZE, Gilles; GUATTARI, Félix (1991). O que é a filosofia?. Rio de Janeiro: Ed. 34, 1992.

GILSON, Étienne (1962). A filosofia na idade média. São Paulo: Martins Fontes, 2001.

HARDT, Michael (1993). Gilles Deleuze: um aprendizado em filosofia. São Paulo: Ed. 34, 1996.

HARDT, Michael. Gilles Deleuze: an Apprenticeship in Philosophy. Disponível em: $<$ http://www.duke.edu/ hardt/>.

ZOURABICHVILI, François. Deleuze: une philosophie de l'événement. Paris: Presses Universitaires de France, 1994. 